\title{
Applying Response Surface Methodology to Optimize the Fenton Oxidation Process in the Removal of Reactive Red 2
}

\author{
Seyyed Alireza Mousavi ${ }^{1 *}$, Samira Nazari ${ }^{2}$ \\ ${ }^{1}$ Department of Environmental Health Engineering and Research Center for Environmental Determinants \\ of Health (RCEDH), Kermanshah University of Medical Sciences, Kermanshah, Iran \\ ${ }^{2}$ Department of Environmental Health Engineering, Kermanshah University of Medical Sciences, Kermanshah, Iran
}

Received: 15 July 2016

Accepted: 26 September 2016

\begin{abstract}
This study evaluated the influence of experimental factors on reactive red 2 oxidation by the Fenton process using response surface methodology (RSM). Experiments were conducted based on a central composite design (CCD) using operating variables such as $\mathrm{H}_{2} \mathrm{O}_{2}, \mathrm{Fe}^{+2}$, and reaction time. The responses were evaluated using a second-order polynomial multiple regression model. The analysis of variance (ANOVA) showed a high coefficient of determination $\left(\mathrm{R}^{2}\right)$ value of more than 0.98 . It confirms a satisfactory adjustment of the second-order regression model with the achieved data. $\mathrm{H}_{2} \mathrm{O}_{2}$ had a significant effect on the removal of RR2 and COD. When the initial concentration of $\mathrm{H}_{2} \mathrm{O}_{2}$ was $90 \mathrm{mg} / \mathrm{l}$, the efficiency of RR2 removal was $94 \%$. The experimental findings were in close agreement with the model prediction.
\end{abstract}

Keywords: reactive red 2, sewage, Fenton's process, hydroxyl radicals, central composite design

\section{Introduction}

Textile industries are known as one of the most important sources of synthetic dyes, which are classified into different groups: acid, reactive, direct, basic, vat, disperse, metal complex, mordant, and sulphur dyes [1-2]. Azo dyes are regarded as the greatest groups of synthetic dyes, which have one or more azo bounds $(-\mathrm{N}=\mathrm{N}-)$, and due to their high solubility, low cost, stability, and color variety are widely used in many applications [1, 3]. Reactive red 2 (RR2) is a reactive azo dye because its strong covalent bond is hard to disintegrate in nature [4].

*e-mail: seyyedarm@yahoo.com
The discharge of textile effluent into the environment, especially receiving waters because of especial characteristics of colored effluents such as complex composition, toxicity, poor degradability, and high solubility, can cause deterioration of environmental quality such as reducing the receiving waters' self-purification capacity and decreasing the rate of photosynthesis. Therefore, in the last few years removing azo dyes has attracted great interest [5-7]. In this regard, numerous physicochemical methods - including precipitation, coagulation, flocculation, adsorption [2], reduction, electrochemical treatment [8], and photo degradation $[9,10]$ - have been used to remove dyes from aqueous solutions $[7,11]$.

Among different methods that have been applied for removing dyes, AOPs are known as the proper 
techniques to remove toxic aqueous pollutants. They are based on producing highly potent oxidants such as hydroxyl radical $\left(\mathrm{OH}^{\circ}\right)$, which has a strong potential to remove pollutants [6]. In recent years, the Fenton process because of high oxidation power, easy operation and maintenance, rapid oxidation kinetics, and relatively low cost and effectiveness has been successfully used as a reagent for removing pollutants from different media [12-13]. Fenton's reagent (FR) has been applied to treat inorganic and organic components such as phenol, LAS, atrazine, trihalomethanes, and textile sewage [1, 13-17]. According to the different studies that have applied the Fenton process, this reagent is affected by concentrations of oxidant $\left(\mathrm{H}_{2} \mathrm{O}_{2}\right)$, catalyst $\left(\mathrm{Fe}^{+2}\right)$, and contaminant. Furthermore, other parameters such as contact time, $\mathrm{pH}$, and temperature are important factors that affect the efficiency of process $[12,14]$. Therefore, optimizing them has a significant effect on the selecting process by operators of sewage treatment sectors.

The present work was undertaken to develop experimental tests employing the Fenton oxidation process in treating RR2 from synthetic solution. In this regard, it developed a model that provides optimum concentration of catalyst $\left(\mathrm{FeSO}_{4}\right)$, oxidant $\left(\mathrm{H}_{2} \mathrm{O}_{2}\right)$, and oxidation time by using central composite design (CCD) and response surface methodology (RSM) as mathematical and statistical techniques that are useful for analyzing the effects of several independent variables in the response [18-19].

\section{Materials and Method}

\section{Chemical and Feeding}

Lab-grade RR2 with formula $\left(\mathrm{C}_{10} \mathrm{H}_{10} \mathrm{C}_{12} \mathrm{~N}_{6} \mathrm{O}_{7} \mathrm{~S}_{22} \mathrm{Na}\right.$; $98 \%$; Fig. 1), Ferrous Soulphat $\left(\mathrm{FeSO}_{4} \cdot 7 \mathrm{H}_{2} \mathrm{O} ; 99.5 \%\right.$ ), and hydrogen peroxide $\left(\mathrm{H}_{2} \mathrm{O}_{2}, 35 \% \mathrm{~W} / \mathrm{W}\right)$ were supplied by E. Merck, Germany. A $50 \% \mathrm{H}_{2} \mathrm{SO}_{4}$ solution was used to prepare its one molar solution, which is used to adjust $\mathrm{pH}$ at 3 . A $50 \% \mathrm{NaOH}$ stock solution was used to prepare its one molar solution, which is used to stop the Fenton reaction at the wanted reaction times.<smiles>[M]OS(=O)(=O)c1cc(Nc2nc(Cl)nc(Cl)n2)c2c(O)c(N=Nc3ccccc3)c(S(=O)(=O)O[Na])cc2c1</smiles>

\section{Experimental Method}

Batch reactors were employed in this work using six series of Pyrex glass with working volume $1 \mathrm{~L}$, each flax was applied for specific concentration of Fenton reagent at different reaction times throughout a cycle with sequencing stages of react, settle, and decant. Settle, decant, and fill stages were always accomplished within 1 hour. The flaxes were filled to capacity of $1 \mathrm{~L}$ by stock RR2 solution with initial concentration of $10 \mathrm{mg} / \mathrm{L}$. Then $\mathrm{pH}$ was adjusted at 3 with a lab $\mathrm{pH}$ meter (model E537). Furthermore, hydrogen peroxide was used as a variable at the arranged concentrations of 10,50 , and $90 \mathrm{mg} / \mathrm{L}$. The concentrations of $\mathrm{Fe}^{+2}$ as catalysts 10,50 , and $90 \mathrm{mg} / \mathrm{L}$ were tested in this study.

\section{Sample Preparation and Analytical Methods}

In the case of designed experiments, sampling was carried out after the aforementioned reaction time. Using $0.45 \mu \mathrm{m}$ filter papers, the collected supernatants were filtered and analyzed every day for RR 2 by a Jenway 6305 spectrophotometer at $\lambda \max 645 \mathrm{~nm}$. Chemical oxygen demand (COD) was determined according to standard methods [20], and $\mathrm{pH}$ was adjusted with a Meter Lab E537 pH meter. All the tests were carried out in triplicate to fulfill reproducibility.

\section{Experimental Design and Data Analysis}

Design-Expert software (version 8.0.0) was applied for the statistical design of the experiments and data analysis through the CCD technique and response surface methodology. RSM is a statistical technique that can be used to optimize and model of achieved experimental data through three steps: statistical design of experiments, assessing the coefficients in a mathematical model and predicting the responses, and examining the adequacy of the model [21]. A standard RSM design called central composite design is a suitable method to fit a quadratic surface. The application of this method allows us to estimate the synergetic or antagonist effect of factors with a minimum number of experiments, as well as to analyze the interaction between them [22]. The aforementioned ability of RSM using the CCD was quite enough to use this method to design the experimental works, to optimize the obtained data, and to study the interactive effects of main factors. The number of runs calculated is based on CCD according to the relation $2 n+2 n+n c$ (where $n$ is the number of factors and nc is the number of center points). The center points are developed to evaluate the experimental error and the reproducibility of the data [23]. The experimental data was analyzed and modeled through an empirical second-degree polynomial as Equation 1 [24].

Fig. 1. Chemical structure of reactive red 2. 
$Y=\beta_{\circ}+\sum_{i=1}^{k} \beta_{i} x_{i}+\sum_{i=1}^{k} \beta_{i i} x_{i}^{2}+\sum_{i<j}^{k} \sum \beta_{i j} x_{i} x_{j}+e$

...where $\mathrm{i}$ represents the linear coefficient, $\mathrm{j}$ stands for the quadratic coefficients, $\beta$ is the regression coefficient, $\mathrm{x}$ represents independent variables, $\mathrm{k}$ is the number of studied and optimized factors in the experiment, and e is the random error.

The modeling process was fulfilled by analysis of variance (ANOVA) for concentrations of $\mathrm{H}_{2} \mathrm{O}_{2}$ and $\mathrm{Fe}^{+2}$ and reaction time as independent factors with two main responses: dye removal and COD removal. According to Table 1, the CCD includes eight factorial points, six axial points, and center point with six additional experimental trials as the replicates of this point. The term of coded value was used to present independent variables at three levels: -1 (minimum), 0 (central), and +1 (maximum). The accuracy of the polynomial model was explicated by the coefficient of determination $\mathrm{R}^{2}$. In addition, model terms were selected or rejected based on the $\mathrm{P}$ value with $95 \%$ confidence levels. Surface plot (three-dimensional) and respective contour plots (two-dimensional) were provided for removing RR2 and COD based on the effects of $\mathrm{H}_{2} \mathrm{O}_{2}$ and $\mathrm{Fe}^{+2}$ doses in the actual values (AV) at different reaction times.

\section{Results and Discussion}

\section{Development of Mathematical Model}

The results of modeling using RSM and CCD based on achieved data are summarized in Table 2. RR2 and COD are dye removal and COD removal in terms of coded factors (CF), and actual factors (AF) for $\mathrm{H}_{2} \mathrm{O}_{2}, \mathrm{Fe}^{+2}$, and reaction time. The amount of the coefficients for $\mathrm{A}$, $\mathrm{B}$, and $\mathrm{C}$ in models confirms the more effective role of $\mathrm{H}_{2} \mathrm{O}_{2}$ concentration and the inferior effect of $\mathrm{Fe}^{+2}$ dosage in removing the dye and COD. According to the results of statistical analysis that have been denoted in Table 2, "model F-value" for percentage removal of dye and COD were 923 and 64, respectively. The value of "Prob- F" was 0.0001 for achieved data. The Prob $-\mathrm{F}>0.05$ indicates that model terms are significant $[21,24]$; therefore, the model is significant and there is only a $0.01 \%$ chance that a "model F-value" this large could occur due to noise. In this case $\mathrm{A}, \mathrm{C}, \mathrm{A}^{2}$, and $\mathrm{B}^{2}$ are significant model terms. Values greater than 0.1 indicate that the model terms are not significant. Adequate precision measures the ratio of signal to noise, and a ratio greater than 4 is desirable [24-25]. According to Table 2, a ratio of 24.65 indicates an adequate signal. This model can be used to navigate the design space. The "Pred. R-Squared" of 0.98 is in reasonable agreement with the "Adj. R-Squared" of 0.99.

Table 1. Results of experiments according to CCD for three-level factorial of variables.

\begin{tabular}{|c|c|c|c|c|c|}
\hline Run & $\begin{array}{l}\text { Factor A: } \mathrm{H}_{2} \mathrm{O}_{2} \\
(\mathrm{mg} / \mathrm{L})\end{array}$ & $\begin{array}{c}\text { Factor B: Fe } \\
(\mathrm{mg} / \mathrm{L})\end{array}$ & $\begin{array}{l}\text { Factor C: time } \\
\text { (h) }\end{array}$ & $\begin{array}{l}\text { Response } 1: \\
\text { (\% dye removal) }\end{array}$ & $\begin{array}{c}\text { Response } 1: \\
(\% \text { COD removal })\end{array}$ \\
\hline 1 & 50 & 90 & 10 & 85 & 90 \\
\hline 2 & 10 & 10 & 5 & 30.13 & 34 \\
\hline 3 & 50 & 50 & 10 & 93 & 93.7 \\
\hline 4 & 50 & 50 & 10 & 93 & 93.7 \\
\hline 5 & 50 & 50 & 10 & 93 & 93.7 \\
\hline 6 & 50 & 50 & 10 & 93 & 93.7 \\
\hline 7 & 10 & 10 & 15 & 37 & 46 \\
\hline 8 & 10 & 50 & 10 & 46 & 60 \\
\hline 9 & 10 & 90 & 5 & 28.1 & 25 \\
\hline 10 & 90 & 90 & 5 & 84.7 & 83.3 \\
\hline 11 & 50 & 50 & 5 & 84.6 & 83.3 \\
\hline 12 & 90 & 50 & 10 & 98 & 96 \\
\hline 13 & 50 & 10 & 10 & 82 & 84 \\
\hline 14 & 50 & 50 & 15 & 96 & 95.83 \\
\hline 15 & 10 & 90 & 15 & 40 & 58 \\
\hline 16 & 50 & 50 & 10 & 93 & 93.7 \\
\hline 17 & 50 & 50 & 10 & 93 & 93.7 \\
\hline 18 & 90 & 10 & 5 & 93.69 & 81.25 \\
\hline 19 & 90 & 10 & 15 & 88 & 96 \\
\hline 20 & 90 & 90 & 15 & 89 & 93.8 \\
\hline
\end{tabular}


Table 2. Developed quadratic models and ANOVA results using Design Expert 8.0.0 for studied responses.

\begin{tabular}{|c|c|c|c|c|c|c|c|c|c|}
\hline Response & $\begin{array}{c}\text { Final model with significant } \\
\text { terms coded factors }(\mathrm{CF}) \\
\text { and actual factors(AF) }\end{array}$ & Prob > F" & $\mathrm{R}^{2}$ & Adj. $R^{2}$ & $\begin{array}{c}\text { PredictedR- } \\
\text { Squared }\end{array}$ & $\begin{array}{l}\text { Adequate } \\
\text { Precision }\end{array}$ & $\mathrm{CV}$ & PRESS & $\begin{array}{l}\text { Sequential } \\
\text { p-value }\end{array}$ \\
\hline $\begin{array}{l}\text { Dye } \\
\text { removal } \\
(\%)\end{array}$ & $\begin{array}{l}\text { CF: Dye }=+92.96+26.22 * \\
\mathrm{~A}+0.60 * \mathrm{~B}+3.88 * \mathrm{C} \\
+0.13 * \mathrm{~A} * \mathrm{~B}-1.27 * \mathrm{~A} * \mathrm{C}+0.63 \\
* \mathrm{~B} * \mathrm{C}-20.90 * \mathrm{~A}^{2}-9.40 * \mathrm{~B}^{2}- \\
2.60 * \mathrm{C}^{2} \\
\mathrm{AF}: \mathrm{Dye}=-7.45426+2.02103 * \\
\mathrm{~A}+0.56696 * \mathrm{~B} \\
+3.01550 * \mathrm{C}+8.12500 \mathrm{E}-005 \\
* \mathrm{~A} * \mathrm{~B}-6.35000 \mathrm{E}-003 * \mathrm{~A} \\
* \mathrm{C}+3.13750 \mathrm{E}-003 * \mathrm{~B} * \\
\mathrm{C}-0.013062 * \mathrm{~A}^{2}-5.87443 \mathrm{E}-003 \\
* \mathrm{~B}^{2}-0.10396 * \mathrm{C}^{2}\end{array}$ & $<0.0001$ & 0.99 & 0.99 & 0.98 & 84.3 & 1.5 & 155 & $<0.0001$ \\
\hline $\begin{array}{l}\text { COD } \\
\text { removal } \\
(\%)\end{array}$ & $\begin{array}{l}\mathrm{CF}: \mathrm{COD}=+94.06+22.73 * \mathrm{~A} \\
+0.88 * \mathrm{~B}+8.28 * \mathrm{C}-0.39 * \mathrm{~A} \\
* \mathrm{~B}-2.47 * \mathrm{~A} * \mathrm{C}+2.09 * \mathrm{~B} * \\
\mathrm{C}-16.61 * \mathrm{~A}^{2}-7.61 * \mathrm{~B}^{2}-5.04 * \mathrm{C}^{2} \\
\mathrm{AF}: \mathrm{COD}=-11.57820+1.74210 \\
* \mathrm{~A}+0.40523 * \mathrm{~B}+5.78353 \\
* \mathrm{C}-2.46094 \mathrm{E}-004 * \mathrm{~A} * \\
\mathrm{~B}-0.012344 * \mathrm{~A} * \mathrm{C}+0.010469 \\
* \mathrm{~B} * \mathrm{C}-0.010380 * \mathrm{~A}^{2}- \\
4.75483 \mathrm{E}-003 * \mathrm{~B}^{2}-0.20171 * \mathrm{C}^{2}\end{array}$ & $<0.0001$ & 0.98 & 0.96 & 0.73 & 24.6 & 5 & 2475 & $<0.0001$ \\
\hline
\end{tabular}

A: $\mathrm{H}_{2} \mathrm{O}_{2}, \mathrm{~B}: \mathrm{Fe}^{+2}, \mathrm{R}^{2}$ : determination coefficient, Adj. $\mathrm{R}^{2}$ : adjusted $\mathrm{R}^{2}, \mathrm{SD}$ : standard deviation, $\mathrm{CV}$ : coefficient of variation, PRESS: predicted residual error sum of squares.

\section{Effect of $\mathrm{H}_{2} \mathrm{O}_{2}$ Concentration}

In order to investigate the effect of $\mathrm{H}_{2} \mathrm{O}_{2}$ concentration on RR2 degradation, experiments were conducted at different $\mathrm{H}_{2} \mathrm{O}_{2}$ concentrations from 10 to $90 \mathrm{mg} / \mathrm{L}$ in $1 \mathrm{ab}$ conditions while keeping the dye concentration at $10 \mathrm{mg} / \mathrm{L}$ and $\mathrm{pH}$ at 3 . In the Fenton process, $\mathrm{H}_{2} \mathrm{O}_{2}$ concentration plays a critical role in contaminant removal efficiency. The results of color removal for $10 \mathrm{mg} / \mathrm{L}$ of RR2 for determining optimum $\mathrm{H}_{2} \mathrm{O}_{2}$ concentration are illustrated in Table 1. As shown in Table 1, by increasing $\mathrm{H}_{2} \mathrm{O}_{2}$ concentration from $10 \mathrm{mg} / \mathrm{L}$ to $90 \mathrm{mg} / \mathrm{L}$, the removal efficiency of RR2 increased from $46 \%$ to $98 \%$, when the catalyst and reaction time were $50 \mathrm{mg} / \mathrm{L}$ and $10 \mathrm{~min}$, respectively. According to the results, COD removal was $95.8 \%$ at $80 \mathrm{mg} / \mathrm{L}$ of $\mathrm{H}_{2} \mathrm{O}_{2}$ as shown in Fig. 1. This result indicates the minimum yielding 34\% COD removals at $10 \mathrm{mg} / \mathrm{L}$ of $\mathrm{H}_{2} \mathrm{O}_{2}$ according to aforementioned results in Table 1. By increasing the concentration of $\mathrm{H}_{2} \mathrm{O}_{2}$ up to 90 $\mathrm{mg} / \mathrm{L}$ we did not show significant improvement in COD removal, and by increasing it to $100 \mathrm{mg} / \mathrm{L}$ the efficiency decreased to $90 \%$, which can be due to self-decomposition of $\mathrm{H}_{2} \mathrm{O}_{2}$ according to Equation (2).

Several researchers have studied the effect of initial concentration of $\mathrm{H}_{2} \mathrm{O}_{2}$ on the degradation of organic compounds using the Fenton process. They confirmed that choosing the suitable concentration of $\mathrm{H}_{2} \mathrm{O}_{2}$ is important for two reasons:
1) The excess $\mathrm{H}_{2} \mathrm{O}_{2}$ reacts with ferric ion $\left(\mathrm{Fe}^{3+}\right)$ to form a weaker hydroperoxyl radical $\left(\mathrm{HO}_{2}{ }^{\circ}\right)$ as presented in Equations (3) and (4), which is not as active as ${ }^{\circ} \mathrm{OH}$ radicals as confirmed by many researchers [7, 26-29].

2) Due to the high cost of $\mathrm{H}_{2} \mathrm{O}_{2}$, consuming its excessive value is not cost-effective $[7,10]$.

$$
\begin{gathered}
2 \mathrm{H}_{2} \mathrm{O}_{2} \rightarrow 2 \mathrm{H}_{2} \mathrm{O}+\mathrm{O}_{2} \\
\mathrm{H}_{2} \mathrm{O}_{2}+\mathrm{Fe}^{3+} \rightarrow \mathrm{Fe}^{2+}+\mathrm{H}^{+}+\mathrm{HO}_{2}^{\circ} \\
\mathrm{H}_{2} \mathrm{O}_{2}+\mathrm{HO}^{\circ} \rightarrow \mathrm{HO}_{2}^{\circ}+{ }^{\circ} \mathrm{OH}_{2}
\end{gathered}
$$

Figs 2 and 3 shows the percentage of removing dye and $\mathrm{COD}$ as a function of the initial concentration of $\mathrm{H}_{2} \mathrm{O}_{2}$ and $\mathrm{Fe}^{2+}$. The response contour (2a and 3a) and response surface plot ( $2 b$ and $3 b$ ) in Figs 2 and 3 for different dosages of $\mathrm{H}_{2} \mathrm{O}_{2}$ and $\mathrm{Fe}^{2+}$ are shown at constant concentration of dye $(10 \mathrm{mg} / \mathrm{L})$ and reaction time $10 \mathrm{~min}$. From Figs 2 and 3 it is clear that the percentage removal of dye and COD removal increased with increasing $\mathrm{H}_{2} \mathrm{O}_{2}$ until $80 \mathrm{mg} / \mathrm{L}$. The effect of the Fenton process on the removal of two direct dyes, blue 2B (B54) and red 12B (R31), in aqueous solution has been studied by Malik and Saha (2003). The results denoted that the degradation rate depends on the initial concentrations of $\mathrm{H}_{2} \mathrm{O}_{2}$ [28]. Lin et al. (1997) confirmed that when $\mathrm{H}_{2} \mathrm{O}_{2}$ starts to be unused in solution, 

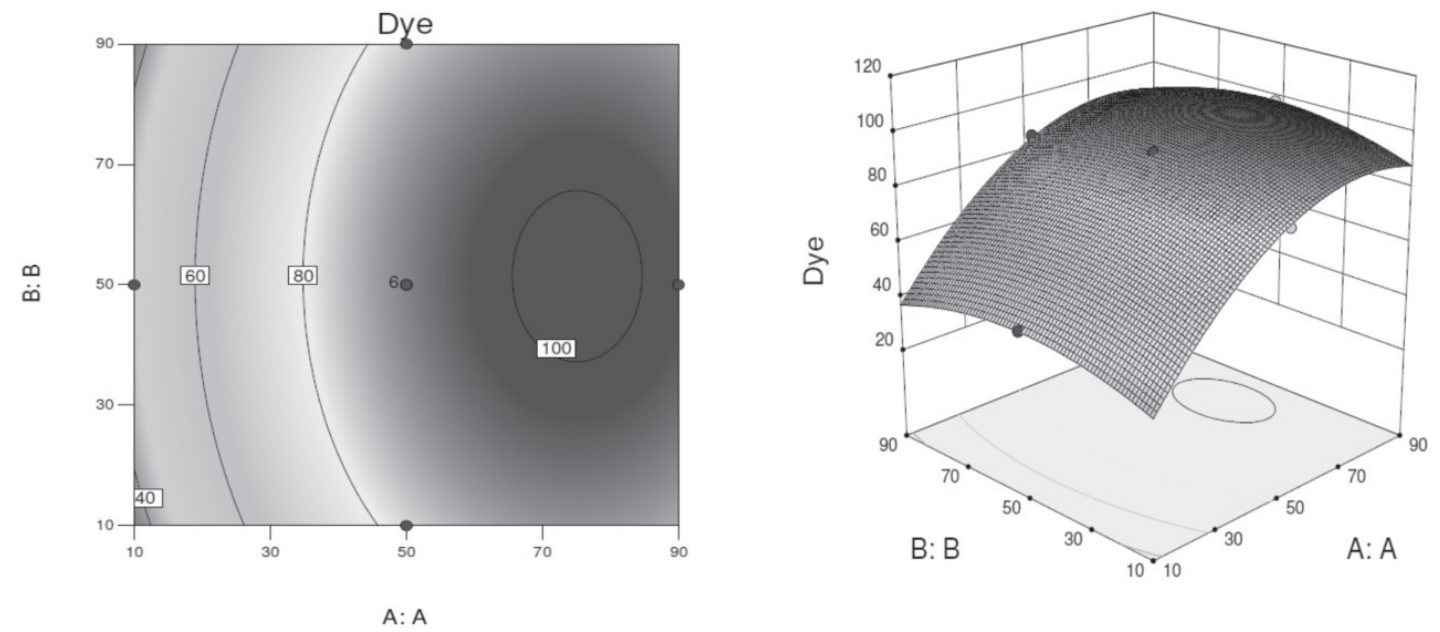

Fig. 2. The response contour plots and response surface plots of dye (a and b) as response affected by variables $\mathrm{H}_{2} \mathrm{O}_{2}, \mathrm{Fe}^{+2}$, and "reaction time $=10 \mathrm{~min}$ " in the Fenton process.
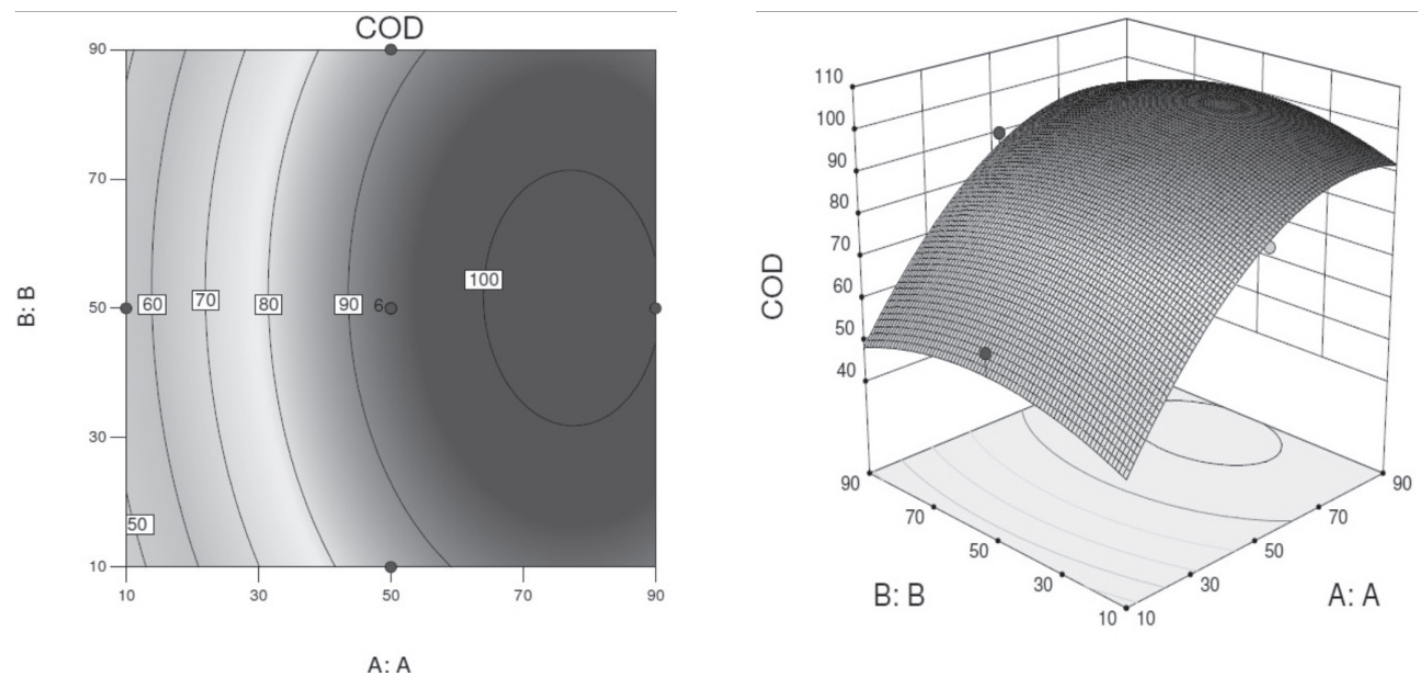

Fig. 3. The response contour plots and response surface plots of COD (a and b) as response affected by variables $\mathrm{H}_{2} \mathrm{O}_{2}, \mathrm{Fe}^{+2}$, and reaction time $=10 \mathrm{~min}$ in the Fenton process.

the time can be considered as the end of the reaction time [27]. Jafari et al. (2014) mentioned the significant effect of hydrogen peroxide on the removal of azo dyes (RB-19 and RR-198) from aqueous solution. The result showed when the $\mathrm{H}_{2} \mathrm{O}_{2} / \mathrm{Fe}^{2+}$ ratio increased, the process led to greater oxidation of dye and optimum $\mathrm{H}_{2} \mathrm{O}_{2}$ dosage was $11 \mathrm{mM}$. They mentioned that the decrease in removal efficiency at a high dosage of $\mathrm{H}_{2} \mathrm{O}_{2}$ was due to the hydroxyl radical scavenging effect of $\mathrm{H}_{2} \mathrm{O}_{2}$ and the recombination of the hydroxyl radical [30]. Based on achieved results from previous research, applying stepwise for the $\mathrm{H}_{2} \mathrm{O}_{2}$ addition could be more effective than using a large initial dosage [30-31].

\section{The Effect of $\mathrm{Fe}^{2+}$ Concentration}

The effect of $\mathrm{Fe}^{2+}$ concentration on dye and COD removal efficiency for $10 \mathrm{mg} / \mathrm{L}$ of $\mathrm{RR} 2$ is given in Figs 2 and 3. According to Fig. 2, maximum RR2 removal
(\% 98) for $10 \mathrm{mg} / \mathrm{L}$ of RR2 was obtained by using $50 \mathrm{mg} / \mathrm{L}$ of $\mathrm{Fe}^{2+}$, and $\mathrm{H}_{2} \mathrm{O}_{2}$ and reaction time were kept at $80 \mathrm{mg} / \mathrm{L}$ and 10min, respectively. Although the $90 \mathrm{mg} / \mathrm{L}$ concentration (density) of $\mathrm{Fe}^{2+} \mathrm{COD}$ removal was not high as well as using $50 \mathrm{mg} / \mathrm{L}$ of $\mathrm{Fe}^{2+}$, which may be explained by redox reactions, since $\mathrm{OH}$ radicals might be scavenged by the reaction with the hydrogen peroxide present or with another $\mathrm{Fe}^{2+}$ molecule according to Equations 5 and 6 [23, $29,32]$.

$$
\begin{aligned}
& \mathrm{Fe}^{2+}+\mathrm{HO}^{\circ} \rightarrow \mathrm{Fe}^{3+}+\mathrm{OH}^{\circ} \\
& \mathrm{H}_{2} \mathrm{O}_{2}+\mathrm{HO}^{\circ} \rightarrow \mathrm{HO}_{2}{ }^{\circ}+{ }^{+} \mathrm{OH}_{2}
\end{aligned}
$$

Kavitha and Palanivelu (2005) elucidate the role of $\mathrm{Fe}^{2+}$ ion on the degradation of cresols at different concentrations of $\mathrm{Fe}^{2+}$ ion from 0 to $1 \mathrm{mM}$, when $\mathrm{H}_{2} \mathrm{O}_{2}$ and $\mathrm{pH}$ were $31.64 \mathrm{mM}$ and $3 \mathrm{mM}$, respectively. Results 
showed that the process efficiency increased progressively by increasing $\mathrm{Fe}^{2+}$ ion concentration due to a higher amount of ${ }^{\circ} \mathrm{OH}$ radical generation. Maximum degradation efficiency about $82 \%$ was achieved at $0.90 \mathrm{mM}$ of $\mathrm{Fe}^{2+}$ for $\mathrm{o}-$ and $\mathrm{p}$-cresol, while it is $0.72 \mathrm{mM}$ for $\mathrm{m}$-cresol. A further increase in $\mathrm{Fe}^{2+}$ ion concentration did not correspondingly increase its reactivity, probably due to direct reaction of ${ }^{\circ} \mathrm{OH}$ radical with metal ions as mentioned in Equations 5 and 6 [33]. The results show that the $\mathrm{H}_{2} \mathrm{O}_{2} / \mathrm{Fe}^{2+}$ ratio is an important parameter in Fenton's reactions because it directly influences the quantum yield of ${ }^{\circ} \mathrm{OH}$ generation [34]. Its importance was confirmed by previous studies, including Azami et al. (2013) during optimization of the azo dye removal, methyl red, from the wastewaterapplied Fenton process. The results confirmed that when increasing $\mathrm{Fe}^{2+}$, an increasing pattern is detected in the dye removal ratio, but increasing the $\mathrm{Fe}^{2+}$ more than a specific limit can lead to a fix or decrease the percentage of dye elimination and the optimum ranges of $\mathrm{Fe}^{2+}$ was 0.1-0.4 mM [35]. The results of studies by Jafari et al. (2014) and Tuty Emilia A. et al. (2014) showed that increasing the $\mathrm{Fe}^{2+}$ ion above optimal dosage cannot be the cause of an increase in the removal efficiency because of the tendency of the $\mathrm{HO}^{\wedge \circ}$ to react with $\mathrm{Fe}^{2+}$ and $\mathrm{H}_{2} \mathrm{O}_{2}$ in the oxidation-reduction reaction $[4,30]$.

\section{The Effect of Reaction Time}

The results show that at low doses of FR, degrading dye and COD was low, but by increasing the reaction time from 5 to 15 minutes the dye removal improved at all levels of $\mathrm{H}_{2} \mathrm{O}_{2}$ and $\mathrm{Fe}^{2+}$ dosages (Fig. 4). According to the models that have been developed in this study, the coded factors (CFs) for the effluent concentration of dye as first response represents a coefficient for reaction time of 3.88, which is 6.75 times less than the coefficient for initial concentration of $\mathrm{H}_{2} \mathrm{O}_{2}$ (26.22). This finding proves that reaction time contributed an effective function in time on the effluent concentration of dye less than $\mathrm{H}_{2} \mathrm{O}_{2}$. The result of this study is in agreement with previous investigations on the effect of reaction time. Mousavi et al. (2011) confirmed that in low doses of FR, degrading LAS was very low but by increasing the reaction time from 20 to 80 minutes LAS removal improved to $80 \%$. A further increase of reaction time did not show more effects on process efficiency [22]. Lin and Lo (1997) investigated the effect of reaction time on treatment of desizing sewage by the Fenton process. The result shows that after 120 minutes as the reaction time, degradation did not improve and after this reaction time $\mathrm{H}_{2} \mathrm{O}_{2}$ remained in solution [27]. However, Mousavi et al. (2016) confirmed that the reaction time had a significant effect on the process. While the reaction time increased from $20 \mathrm{~min}$ to $80 \mathrm{~min}$, the percentage removal of Rhodamine B increased from 35\% to $55 \%$, when other parameters were constant [10], but increasing reaction time more than a specific limit cannot lead to improved dye elimination $[7,22,30]$.

\section{Optimization Process}

The experimental results were optimized by DesignExpert software using the generated overlay plot by superimposing the contours of various response surfaces.

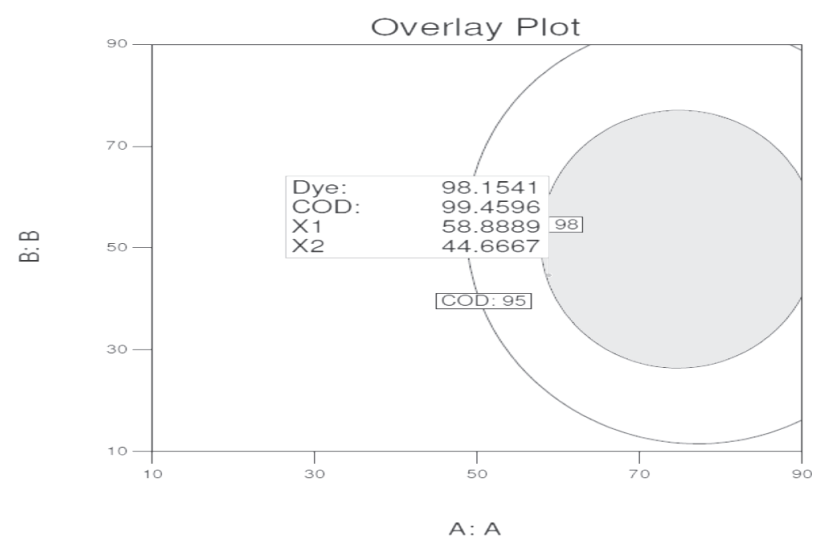

Fig. 5. Overlay plot for optimal region: dye removal $>98 \%$, COD removal $>99 \%$ at different concentrations of oxidant: $\mathrm{H}_{2} \mathrm{O}_{2}(58.8 \mathrm{mg} / \mathrm{L})$, catalyst: $\mathrm{Fe}^{+2}(44.6 \mathrm{mg} / \mathrm{L})$, and reaction time $(11.11 \mathrm{~min})$ a)

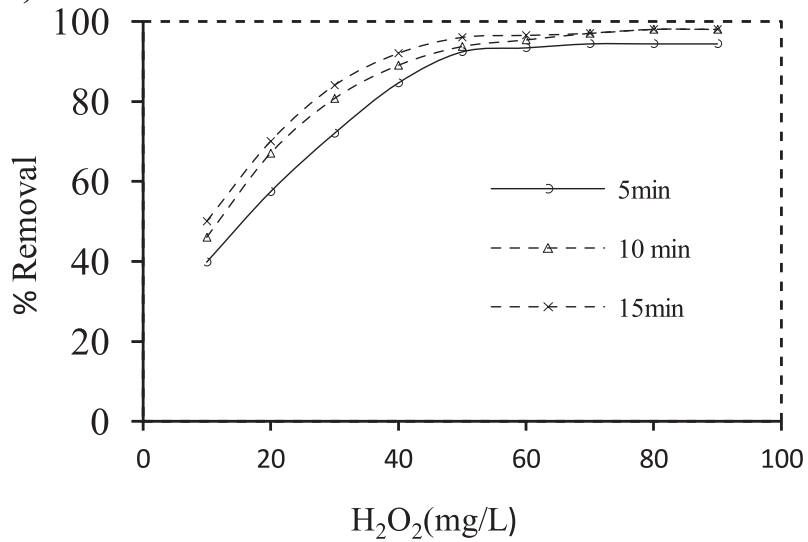

b)

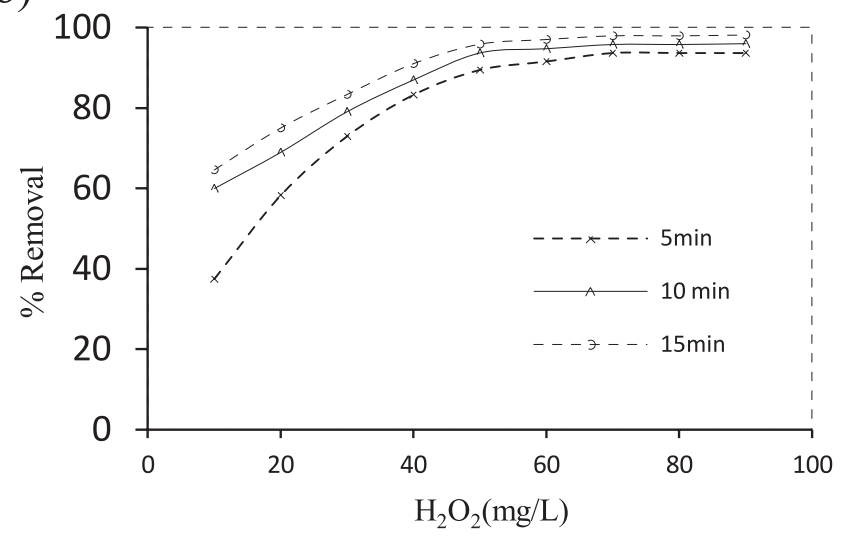

Fig. 4. Effect of reaction time on dye a) and COD b) removal. 
The optimum domain was identified by defining the desired limits of dye and COD removal and the shaded region of the overlay plot, which was considered as a promising value of the dependent variables as shown in Fig. 5. The optimum point of process operating for removing dye and COD was obtained at the $\mathrm{H}_{2} \mathrm{O}_{2}$ of $58 \mathrm{mg} / \mathrm{L}$ and $\mathrm{Fe}^{+2}$ of $44 \mathrm{mg} / \mathrm{L}$. The process was operated in an optimized condition by accomplishing the experiments with optimum variables to confirm a reasonable prediction in the model. The average removing percentage of dye and COD from a repeated (thrice) test was $>98 \%$. The achieved results were in close agreement with the prediction of the model.

\section{Conclusions}

$\mathrm{H}_{2} \mathrm{O}_{2}$ concentration, $\mathrm{Fe}^{2+}$ concentrations, and reaction time play an important role on the Fenton oxidation of selected reactive dye RR2. The results indicate that the most favorable $\mathrm{H}_{2} \mathrm{O}_{2}$ was $80 \mathrm{mg} / \mathrm{L}$ for both dye and COD removal as responses. The results also show that there are no significant differences between different reaction times, when other factors were kept. Sufficient models based on the experimental results of CCD and RSM were employed to better understand the direct effect of such factors as $\mathrm{H}_{2} \mathrm{O}_{2}$ concentration, $\mathrm{Fe}^{2+}$ concentrations, and the reaction time on the process' function and development. The optimum operational conditions were determined as $\mathrm{H}_{2} \mathrm{O}_{2}$ of $58 \mathrm{mg} / \mathrm{L}$ and $\mathrm{Fe}^{2+}$ of $44 \mathrm{mg} / \mathrm{L}$, with $>\% 98$ dye removal.

\section{Acknowledgements}

The authors sincerely thank the Department of Environmental Health Engineering in Kermanshah University of Iran for laboratory support of this project.

\section{References}

1. RAHMANI A.R., ZARRABI M., SAMARGHANDI M. R., AFKHAMI A., GHAFFARI H. R. Degradation of Azo Dye Reactive Black 5 and acid orange 7 by Fenton-like mechanism. Iranian Journal of Chemical Engineering, 7 (1), 87, 2010.

2. MOUSAVI S.A., KHASHIJ M., SHAHBAZI P. Adsorption Isotherm Study and Factor Affected on Methylene Blue Decolorization using Activated Carbon Powder Prepared Grapevine Leaf. Safety Promotion and Injury Prevention, 3 (4), 249, 2016.

3. MUTHANA S.M., AYAD F.A., LUMA M.A., FALAH H.H. Zinc oxide assisted photocatalytic decolorization of reactive red 2 dye. Int. J. Chem. Sci., 9 (3), 969, 2011.

4. TUTY E.A., YOURDAN W.A., FEBRIAN M. Degradation of reactive red 2 by Fenton and photo-Fenton oxidation processes. ARPN Journal of Engineering and Applied Sciences, 11 (8), 5227, 2016.

5. QU BAOCHENG Z.J., XIANG X., ZHENG C., ZHAO H., ZHOU X. Adsorption behavior of Azo Dye CI Acid Red 14 in aqueous solution on surface soils. Journal of Environmental Sciences, 20 (6), 704, 2008.

6. SHUMAILA K., SHAHZAD A.S. Photo-fenton process: Optimization and decolourization and mineralization of reactive blue 222 dye. Journal of Environmental Science and Water Resources, 1 (11), 267, 2012.

7. BAGHAPOUR M.A., DEHGHANI M. Evaluation of Fenton Process in Removal of Direct Red 81. Journal of health sciences and surveillance system, 4 (1), 14, 2016.

8. SALMANI L.R., AKRAM G., SAEID A., MARYAM D., NASRIN N. Removal of Reactive Red 141 Dye from Synthetic Wastewater by Electrocoagulation Process: Investigation of Operational Parameters. Iranian Journal of Health, Safety and Environment, 3 (1), 403, 2016.

9. ABD E.S., SALAH H., NACHIDA K.M., DJILALI T., TIBOR S., KLÁRA H., LÁSZLÓ N. Using Central Composite Experimental Design to Optimize the Degradation of Tylosin from Aqueous Solution by PhotoFenton Reaction. Materials, 9 (6), 428, 2016.

10. SEYYED ALIREZA M., PARASTOO S., PARVIZ M., SEYYED MAJID D.N. Investigation of the efficiency of $\mathrm{UV} / \mathrm{H}_{2} \mathrm{O}_{2}$ process on the removal of Rhodamine $\mathrm{B}$ from aqueous solutions. 10 (5), 456, 2016.

11. HAFSHEJANI M.K., OGUGBUE C.J., MORAD N. Application of response surface methodology for optimization of decolorization and mineralization of triazo dye Direct Blue 71 by Pseudomonas aeruginosa. 3 Biotech, 4 (6), 605, 2014.

12. NEYENS E., BAEYENS J. A review of classic Fenton's peroxidation as an advanced oxidation technique. Journal of Hazardous Materials, 98 (1), 33, 2003.

13. TANG W.Z., TASSOS S. Oxidation kinetics and mechanisms of trihalomethanes by Fenton>s reagent. Water Research, 31 (5), 1117, 1997.

14. CHAN K., CHU W. Modeling the reaction kinetics of Fenton's process on the removal of atrazine. Chemosphere. 51 (4), 305, 2003.

15. GALLARD H., DE LAAT J. Kinetic modelling of Fe (III) $/ \mathrm{H}_{2} \mathrm{O}_{2}$ oxidation reactions in dilute aqueous solution using atrazine as a model organic compound. Water Research, 34 (12), 3107, 2000.

16. GRYMONPRÉ D.R., AMIT K. S.,WRIGHT C.F., BRUCE R.L. The role of Fenton's reaction in aqueous phase pulsed streamer corona reactors. Chemical Engineering Journal, 82 (1), 189, 2001.

17. LIN S.H., LEU H.G., Operating characteristics and kinetic studies of surfactant wastewater treatment by Fenton oxidation. Water Research, 33 (7), 1735, 1999.

18. DRAPER N.R., Applied regression analysis bibliography update 1994-97. Communications in Statistics-Theory and Methods, 27 (10), 2581, 1998.

19. MASON R.L., GUNST R.F., HESS J.L. Statistical design and analysis of experiments: with applications to engineering and science. Second edition, John Wiley \& Sons. 2003.

20. RICE E.W., BRIDGEWATER L., A.P.H. Association, Standard methods for the examination of water and wastewater: American Public Health Association Washington, DC. 2012.

21. MOUSAVI S., IBRAHIM S., AROUA M.K. Sequential nitrification and denitrification in a novel palm shell granular activated carbon twin-chamber upflow bio-electrochemical reactor for treating ammonium-rich wastewater. Bioresource technology,. 125, 256, 2012.

22. MOUSAVI S., MAHVI A.H., NASSERI S. GHAFARI SH. Effect of Fenton process $\left(\mathrm{H}_{2} \mathrm{O}_{2} / \mathrm{Fe}^{2+}\right)$ on removal of linear alkylbenzene sulfonate (LAS) using centeral composite 
design and response surface methodology. Iranian Journal of Environmental Health Science \& Engineering, 8 (2), 111, 2011.

23. GHAEDI M., KOKHDAN S.N. Removal of methylene blue from aqueous solution by wood millet carbon optimization using response surface methodology. Spectrochimica Acta Part A: Molecular and Biomolecular Spectroscopy.136, 141, 2015.

24. MONTGOMERY D.C., Design and analysis of experiments, John Wiley \& Sons. 2008.

25. MOUSAVI S.A., IBRAHIM S. Application of response surface methodology (RSM) for analyzing and modeling of nitrification process using sequencing batch reactors. Desalination and Water Treatment, 57 (13), 5730, 2016.

26. HSUEH C.L., HUANG Y.H., WANG C.C., CHEN C.Y. Degradation of azo dyes using low iron concentration of Fenton and Fenton-like system. Chemosphere, 58 (10), 1409, 2005.

27. LIN S.H., LO C.C., Fenton process for treatment of desizing wastewater. Water Research, 31 (8), 2050, 1997.

28. MALIK P., SAHA S. Oxidation of direct dyes with hydrogen peroxide using ferrous ion as catalyst. Separation and Purification Technology, 31 (3), 241, 2003.

29. CHATTERJEE S., ATUL K., SRABANTI B., SUSMITA D. Application of response surface methodology for methylene blue dye removal from aqueous solution using low cost adsorbent. Chemical Engineering Journal, 181, 289, 2012.

30. HOSSEIN J.M., EDRIS B., AHMADREZA Y., MOSTAFA

A. Removal of azo dyes from aqueous solution using fenton and modified fenton processes. Health Scope, 3 (2), 15507, 2014.

31. HUANG Y.-F., CHANGA P-S., CHENA C.-Y. Comparative study of oxidation of dye-Reactive Black B by different advanced oxidation processes: Fenton, electro-Fenton and photo-Fenton. Journal of Hazardous Materials, 154 (1), 655, 2008.

32. LUCAS M.S. PERES J.A. Removal of COD from olive mill wastewater by Fenton>s reagent: Kinetic study. Journal of Hazardous Materials, 168 (2), 1253, 2009.

33. KAVITHA V. PALANIVELU K. Destruction of cresols by Fenton oxidation process. Water Research, 39 (13), 3062, 2005.

34. SUN J.-H., SHIA S.-H., LEEA Y.-F., SUN S.-P. Fenton oxidative decolorization of the azo dye Direct Blue 15 in aqueous solution. Chemical Engineering Journal, 155 (3), 680, 2009.

35. AZAMI M., BAHRAM M., NOURI S., Central composite design for the optimization of removal of the azo dye, Methyl Red, from waste water using Fenton reaction. Current Chemistry Letters, 2 (2), 57, 2013. 